\title{
The effects of US state income inequality and alcohol policies on symptoms of depression and alcohol dependence
}

\author{
Claire Henderson $^{\mathrm{a}, *}$, Xinhua Liu ${ }^{\mathrm{b}, \mathrm{c}}$, Ana V. Diez Roux ${ }^{\mathrm{e}}$, Bruce G. Link ${ }^{\mathrm{d}}$, \\ Deborah Hasin ${ }^{\mathrm{d}, \mathrm{f}}$ \\ ${ }^{a}$ Health Services Research Department, David Goldberg Centre, Institute of Psychiatry, De Crespigny Park, P.O. 29 , \\ London SE5 8AF, UK \\ ${ }^{\mathrm{b}}$ Division of Biostatistics, New York State Psychiatric Institute, New York, NY 10032, USA \\ ${ }^{\mathrm{c}}$ Department of Biostatistics, Mailman School of Public Health, Columbia University, New York, NY 10032, USA \\ ${ }^{\mathrm{d}}$ Department of Epidemiology, Mailman School of Public Health, Columbia University, New York, NY 10032, USA \\ ${ }^{\mathrm{e}}$ Center for Social Epidemiology and Population Health, University of Michigan, 1214 S. University 2nd Floor, Ann Arbor, \\ MI 48104-2548, USA \\ ${ }^{\mathrm{f}}$ Department of Psychiatry, College of Physicians and Surgeons, Columbia University, New York, NY 10032, USA
}

\begin{abstract}
Mental health is likely to be influenced by contextual variables that emerge only at the level of the group. We studied the effect of two such group-level variables, within-state income inequality and alcohol tax policy, on symptoms of current depression and alcohol dependence in a US national sample, controlling for state-level and individual characteristics. A cross-sectional US national probability sample provided the individual-level data. State income data were obtained from the 1990 US census. The Gini coefficient (raw and adjusted) indicated income inequality. Outcome measures included current symptoms of depression and alcohol dependence. Controlling for individual-level variables and state median income, the odds of depressive symptoms was not positively associated with state income inequality. Controlling for individual-level variables, state median income and alcohol distribution method, a weak negative association between Gini and alcohol dependence was observed in women, but this association disappeared after additional adjustment for beer tax. No association was observed in men. Higher state beer tax was significantly associated with lower prevalence of alcohol dependence symptoms for both men and women. The results suggest that state income inequality does not increase the experience of alcohol dependence or depression symptoms. However, evidence was found for a protective effect of increased beer taxation against alcohol dependence symptoms, suggesting the need to further consider the impact of alcohol policies on alcohol use disorders.
\end{abstract}

(C) 2003 Elsevier Science Ltd. All rights reserved.

Keywords: Income inequality; Beer tax; Socioeconomic factors; Depression; Alcohol dependence; USA

\section{Introduction}

The recent resurgence in interest in social epidemiology (Link \& Phelan, 2000) has included the identification of contextual variables that emerge only at the level of the group. Such variables are aspects of the

\footnotetext{
*Corresponding author. Tel.: +44-20-7848-0729; fax: + 44-20-7277-1462.

E-mail address: c.henderson@iop.kcl.ac.uk (C. Henderson).
}

environmental context of health, which is omitted if only individual-level data is measured (Susser, 1994). For example, the notion that inequality in the distribution of income may be related to health has recently attracted much attention. Wilkinson's (1992) original report of an association between income inequality and mortality in developed countries has since been replicated for states and metropolitan areas within the US (Lynch et al., 1998; Kaplan, Pamuk, Lynch, Cohen, \& Balfour, 1996; Kennedy, Kawachi, \& Prothrow-Stith, 
1996). These associations, however, do not appear to be as strong in some contexts, as demonstrated by the weaker relationship between income inequality and mortality observed across Canadian provinces (Ross et al., 2000). Further work has examined the extent to which the relation between income inequality and health persists once individual-level factors such as income are controlled for. The relationship has been found to persist in some (Kennedy, Kawachi, Glass, \& ProthrowStith, 1998; Kahn, Wise, Kennedy, \& Kawachi, 2000; Diez-Roux, Link, \& Northridge, 2000; Lochner, Pamuk, Makuc, Kennedy, \& Kawachi, 2001) but not all studies (Fiscella \& Franks, 1997; Daly, Duncan, Kaplan, \& Lynch, 1998; Osler et al., 2002; Shibuya, Hashimoto, \& Yano, 2002; Sturm \& Gresenz, 2002). There is still substantial ongoing debate regarding the presence and strength of an inequality effect, over and above the wellestablished effect of individual-level income (Wilkinson, 2002; Lynch \& Davey Smith, 2002).

Wilkinson $(1992,1997 \mathrm{a}, \mathrm{b})$ has suggested that income inequality affects both physiology (for example, due to endocrine changes) and stress-related behaviors that affect health, for example, stress-related smoking, drinking, comfort eating and interpersonal violence. It has also been hypothesized that the negative effects of living in an unequal society may be greater in persons of lower income (Kennedy et al., 1998; Kahn et al., 2000; Diez-Roux et al., 2000). To the extent that stress is causally related to common mental health problems (for example, Kendler et al., 1995), this interpretation implies that those living in areas of greater income inequality will have higher rates of mental health problems, particularly those on lower incomes. One study on maternal mental health (Kahn et al., 2000) was consistent with this hypothesis, while two more, on adults in the US (Sturm \& Gresenz, 2002) and the UK (Weich, Lewis, \& Jenkins, 2001) did not find the predicted relationship. All three of these studies addressed mental health outcomes involving depression or anxiety, but did not include alcohol, specifically suggested by Wilkinson as being one of the health conditions affected by income inequality.

To date, state-level information based on a nationally representative sample has not been used to address the relationship of income inequality to common mental health problems including both depression and alcohol. State-level data offers a number of advantages in addressing this question. According to Wilkinson, income inequality becomes important only in areas large enough to contain the relevant social stratification, while in small neighborhoods with little income gradient, morbidity and mortality are more closely related to the average income. The choice of US state to define the geographic area thus provides large geographic units with considerable social heterogeneity (Wilkinson, 1997a). State-level analysis also allows incorporation of potential state-level confounders, such as state alcohol policies, that may influence mental health outcomes such as alcohol dependence through their effects on consumption. An example of such an alcohol policy is excise tax on alcohol, relevant because studies consistently show an inverse relationship between alcohol price and alcohol consumption (Toomey \& Wagenaar, 1999; Chaloupka, Grossman, \& Saffer, 2002). Another such policy includes alcohol distribution methods, which may affect consumption by restricting access (Toomey \& Wagenaar, 1999). Because variation in both of these can be studied at the state level, US state represents a geographical unit of analysis that is meaningful in many respects.

The National Longitudinal Alcohol Epidemiologic Survey (NLAES) presents an unusual opportunity to study the relationship of income inequality and state alcohol policy to depression and alcohol dependence at the state level because the sample is very large and the response rate very high (Grant et al., 1994). Further, well-validated and reliable measures of depression and alcohol disorders were used (Grant \& Hasin, 1992; Grant, Harford, Dawson, Chou, \& Pickering, 1995; Hasin et al., 2003). We therefore assessed the contextual effect of state income inequality on symptoms of depression and alcohol dependence, controlling for potential state- and individual-level confounding variables. The gender distribution of major depression and alcohol dependence are almost mirror opposites of each other (Hanna \& Grant, 1997). Therefore, we investigated each of these disorders separately for men and women.

\section{Data and methods}

\section{Sources of data}

Data from the 1992 NLAES (Grant et al., 1994) were used as the source of individual-level data. The NLAES was sponsored by the National Institute of Alcohol Abuse and Alcoholism, with fieldwork conducted by the US Bureau of the Census. It covers the 48 contiguous US States including the District of Columbia except for Nebraska and North Dakota and has a sample of 42,862. A two-stage design was used to ensure a representative sample of non-institutionalized people aged 18 or over. Oversampling at the second stage (where areas within primary sampling units were selected) was used to ensure sufficient number of African American participants for analysis, while oversampling of 18-29 years old at the household level was undertaken, as this age group has highest levels of substance use. Interviewing took place between October 1991 and November 1992. The household response rate was $91.9 \%$ and the sample person response rate (the 
response rate for persons sampled within the households) was $97.4 \%$. Interviews were conducted face-toface.

Data on income distributions were obtained from the 1990 US Census, for which respondents are asked to give their monthly income as one of 23 categories. These data were used to create variables representing the distributions of households into 23 income categories, median household income and total aggregate income for each state. These variables were then used to calculate the Gini coefficient. The Gini coefficient was used as a measure of income inequality, both as a raw measure and one adjusted for taxes, cash transfers and differences in household composition (Ross, 2000). It represents the area between the $45^{\circ}$ line produced by equally distributed income on a graph of cumulative population income vs. percentage of population and the curve on the same graph produced by unequal income distribution. This measure has been widely used in other studies and correlates well with other commonly used measures (Kawachi \& Kennedy, 1997). The hypothetic range is from 0.0 , representing income equality, to 1.0 , representing maximum inequality. For US states in 1990, the raw Gini coefficient ranges from 0.38 for Minnesota, the state with the lowest level of income equality, to 0.50 for Louisiana, the state with the highest level of income inequality (Kennedy, Kawachi, \& Prothrow-Stith, 1996). Raw and adjusted Gini coefficients were divided into five categories containing roughly equal number of states.

Data on state alcohol policies were obtained from the Alcohol Epidemiology Program (2000). The two policies chosen to generate state-level alcohol policy variables were those that affect the greatest proportion of people and for which the data were most complete. One of these policies was whether distribution of wines and spirits is controlled by State monopoly (as is the case for 18 states) as opposed to a licensure system. The second was the level of beer tax, expressed in cents per drink. Precise figures for 1992 were not available. However, data displayed graphically (Alcohol Epidemiology Program, 2000) showing changes in beer taxation by state since 1992 indicated that very little relative change among states has occurred. For this reason, the figures given for January 1, 2000 were used as a proxy. Beer taxation was divided into five categories that included approximately equal number of states.

\section{Measures of alcohol dependence and depression}

Symptoms of depression and alcohol dependence during the past 12 months were assessed with the Alcohol Use Disorder and Associated Disabilities Interview Schedule (Grant \& Hasin, 1992; Grant et al., 1995). These symptom items can be combined via computer program to produce DSM-IV diagnoses of major depression and alcohol use disorders. For major depression, this includes the nine symptoms of DSM-IV major depression. These are depressed mood, anhedonia, significant weight loss or gain not caused by dieting, insomnia or hypersomnia, psychomotor agitation or retardation, fatigue or loss of energy and worthlessness or guilt. For DSM-IV alcohol dependence, the seven criteria include tolerance, withdrawal/drinking to avoid withdrawal, drinking more or longer than intended, a persistent desire or unsuccessful attempts to cut down or control alcohol use, a great deal of time spent obtaining or using alcohol, giving up or reducing important social, occupational or recreational activities, and continuing to drink despite knowledge of a persistent physical or psychological problem likely to have been caused or exacerbated by drinking.

In the present study, rather than using the diagnoses of major depression or alcohol dependence, we created variables representing one or more symptoms of each disorder. We did this for several reasons. Regarding alcohol dependence, efforts to identify a diagnostic threshold for dependence in general population samples find no more validity for a threshold of three symptoms than at lower or higher thresholds, (Heath et al., 1994; Hasin et al., 2003). Individuals with 1 or 2 DSM-IV alcohol dependence symptoms fall on a continuum on external indicators of dependence severity between those with no symptoms and those with a diagnosis (three or more symptoms) (Muthén, 1996; Hasin \& Paykin, 1998, 1999; Sarr, Bucholz, \& Phelps, 2000). Further, the theoretical basis for the DSM-IV dependence criteria (Edwards \& Gross, 1976) considered dependence to be a dimensional rather than categorical concept. Thus, our approach is consistent with empirical data from general population research as well as theoretical work. Note that we analyzed alcohol dependence symptoms rather than alcohol consumption because having even one symptom is clinically meaningful, while the implications of a given level of consumption differ depending on sex, physiology (White, Altmann, \& Nanchahal, 2002) and numerous other factors.

Regarding major depression, little support was found in twin data for the five-symptom threshold for DSM-IV major depression in terms of predictive power for future depressive episodes (Kendler \& Gardner, 1998), and numerous studies show that subsyndromal depression is accompanied by considerable morbidity (Johnson, Weissman, \& Klerman, 1992; Judd, Paulus, Wells, \& Rapaport, 1996; Olfson et al., 1996; Horwath, Johnson, Klerman, \& Weissman, 1992). We chose not to use the mean number of symptoms reported (for either depression or alcohol dependence) because the majority of the population reported no symptoms of either disorder, and hence the distributions were skewed. The frequencies for number of symptoms reported are shown in Table 1. 
Table 1

Frequencies of symptoms of depression and alcohol dependence

\begin{tabular}{llrlrl}
\hline Count & \multicolumn{2}{l}{$\begin{array}{l}\text { Depression symptoms } \\
\text { (SE) }(\%)\end{array}$} & \multicolumn{2}{l}{$\begin{array}{l}\text { Alcohol dependence } \\
\text { symptoms (SE) }(\%)\end{array}$} \\
\cline { 2 - 3 } \cline { 5 - 6 } \cline { 5 - 6 } & Males & Females & & Males & Females \\
\hline 0 & $76.6(0.46)$ & $72.1(0.46)$ & & $77.9(0.42)$ & $88.9(0.29)$ \\
1 & $12.2(0.32)$ & $12.2(0.28)$ & & $10.2(0.26)$ & $5.5(0.17)$ \\
2 & $4.2(0.17)$ & $5.1(0.18)$ & & $5.6(0.22)$ & $3.00(0.14)$ \\
3 & $2.2(0.13)$ & $2.9(0.14)$ & & $3.1(0.16)$ & $1.4(0.09)$ \\
4 & $1.4(0.10)$ & $1.7(0.10)$ & & $1.5(0.12)$ & $0.7(0.06)$ \\
5 & $0.9(0.08)$ & $1.3(0.09)$ & $0.9(0.09)$ & $0.3(0.05)$ \\
6 & $0.9(0.08)$ & $1.1(0.08)$ & $0.4(0.06)$ & $0.2(0.03)$ \\
7 & $0.6(0.07)$ & $1.3(0.08)$ & $0.3(0.06)$ & $0.08(0.02)$ \\
8 & $0.6(0.06)$ & $1.2(0.08)$ & & \\
9 & $0.5(0.06)$ & $0.9(0.07)$ & & \\
\hline
\end{tabular}

Proportion (se) for males and females are weighted.

\section{Sociodemographic measures for sample characteristics}

On the basis of previous research, several individuallevel sociodemographic variables were identified as potential confounders of the relationship between income inequality and alcohol dependence and depression. For simple bivariate analyses, age was divided into five categories $(18-20,21-30,31-40,41-55$ and 56 or over) to include a youngest group below the minimum legal drinking age of 21 . Race was categorized as nonwhite vs. white. Educational attainment was categorized in years; 0-8 (no high school), 9-11 (some high school), 12 (high school graduate), 13-15 (some college) or 16 or more (college graduate). Family composition was categorized as one (the subject) or two or more related persons living in the same household. Gross family monthly income was divided into 10 categories, the lowest at below $\$ 550$ and the highest at $\$ 9000$ or more per month.

\section{Data analysis}

Analyses were conducted for men and women separately, because of the sex differences in rates for depression and alcohol dependence symptoms (Hanna \& Grant, 1997). We first examined the prevalence of depressive symptoms and the prevalence of alcohol dependence symptoms for each category of risk factors and used the chi-square test to detect bivariate associations between a binary outcome and risk factors. Logistic regression analysis was then applied to the binary outcomes, having any depressive symptoms and having any alcohol dependence symptoms. The final models were then repeated using the DSM-IV diagnoses of Major Depressive Disorder and Alcohol Dependence constructed from the interview. Before conducting regression analysis, we used graphics to check the linear relationship between log odds of a binary outcome and a continuous covariate so that a proper transformation could be used when necessary.

To examine whether the association between income inequality and the outcomes was modified by the demographic variables of interest, we added interaction terms of the raw and adjusted Gini with family income, age and race to separate logistic regression models including main effects together with all other sociodemographic and contextual factors. Age and family income were tested in the same way for interaction with beer taxation. To account for the complex sampling design of NLAES data set and to correct for oversampling, we used Software for Survey Data Analysis (Shah, Barnwell, \& Bieler, 1997). This allows production of proportions with standard errors weighted by sampling probabilities, weighted chi-square tests (see Table 2), and estimation of logistic regression parameters to produce odds ratios (OR) with 95\% confidence intervals (CI) taking into account clustering due to the staged sampling scheme (see Tables 3 and 4).

For each outcome, adjustment was made for median state income and a number of individual-level factors; family size (in the household) and monthly income, age, race, education and urban or rural residence. For alcohol dependence, state beer taxation and controlled vs. licensed distribution of wines and spirits were also included. The $\log$ of family income showed a negative linear relationship with the log odds of having any depressive symptoms. For alcohol dependence, the relationship was positive and linear except for the high rates of dependence symptoms among those in the lowest income category. A separate 'low income' indicator variable was therefore created for the lowest income category vs. the other categories. Because all results were similar for raw and adjusted Gini, only adjusted Gini results are shown.

\section{Results}

The total unweighted sample size is 42,862. Unweighted sample size by state varies from 47 in New Hampshire to 4993 in California. Women were slightly overrepresented in the unweighted sample $(58.4 \%$ women vs. $41.6 \%$ men). Table 2 shows the results of simple bivariate analyses for men and women, testing the null hypothesis of no association between a binary outcome and a risk factor, for characteristics of the weighted study sample and outcome prevalences by individual and state characteristics. A greater proportion of women had had depressive symptoms than men $(27.9 \%$ vs. $23.4 \%)$ while men more commonly had had symptoms of alcohol dependence $(22.1 \%$ vs. $11.0 \%)$. Among men, the prevalence of depressive symptoms was lowest in the lowest Gini category but no trend was 
Table 2

Characteristics of respondents and proportions with any symptoms of depression or alcohol dependence

\begin{tabular}{|c|c|c|c|c|c|}
\hline \multirow{3}{*}{$\begin{array}{l}\text { Characteristic } \\
\text { Total sample }\end{array}$} & \multirow{3}{*}{$\begin{array}{l}\% \\
100\end{array}$} & \multicolumn{2}{|c|}{$\begin{array}{l}\text { Proportion with any depression symptoms, } \\
\text { past } 12 \text { months }(\%)(\mathrm{SE})\end{array}$} & \multicolumn{2}{|c|}{$\begin{array}{l}\text { Proportion with any dependence symptoms, } \\
\text { past } 12 \text { months }(\%)(\mathrm{SE})\end{array}$} \\
\hline & & Men & Women & Men & Women \\
\hline & & $23.4 * * *$ & 27.9 & $22.1 * * *$ & 11.0 \\
\hline \multicolumn{6}{|l|}{ Age(years) } \\
\hline $18-20$ & 5.7 & $30.9(1.7)^{* * *}$ & $35.1(1.7)^{* * *}$ & $37.6(1.8)^{* * *}$ & $24.0(1.8)^{* * *}$ \\
\hline $21-30$ & 19.3 & $26.8(1.0)$ & $30.8(0.9)$ & $39.6(1.0)$ & $21.9(0.7)$ \\
\hline $31-40$ & 23.0 & $23.6(0.8)$ & $27.8(0.7)$ & $24.3(0.7)$ & $13.2(0.5)$ \\
\hline $41-55$ & 26.0 & $20.7(0.7)$ & $26.7(0.8)$ & $16.5(0.7)$ & $8.1(0.4)$ \\
\hline $56+$ & 26.0 & $21.5(0.8)$ & $25.7(0.7)$ & $7.7(0.4)$ & $2.3(0.2)$ \\
\hline \multicolumn{6}{|l|}{ Ethnicity } \\
\hline Non-white & 16.4 & $23.4(0.5)$ & $27.6(0.5)$ & $22.3(0.4)$ & $11.6(0.3)^{* * *}$ \\
\hline White & 83.6 & $23.7(1.0)$ & $29.4(1.0)$ & $21.0(1.1)$ & $8.4(0.5)$ \\
\hline \multicolumn{6}{|c|}{ Family monthly income } \\
\hline$<550$ & 10.2 & $28.5(1.6)^{* * *}$ & $32.4(1.1)^{* * *}$ & $31.3(2.3)^{*}$ & $13.5(1.2)^{*}$ \\
\hline $550-950$ & 12.9 & $28.1(1.5)$ & $32.4(1.1)$ & $21.8(1.2)$ & $9.9(0.6)$ \\
\hline $951-1300$ & 11.7 & $27.1(1.3)$ & $30.2(0.9)$ & $22.5(1.1)$ & $9.4(0.6)$ \\
\hline $1301-1700$ & 10.5 & $26.6(1.4)$ & $27.9(1.0)$ & $19.5(1.1)$ & $10.0(0.7)$ \\
\hline 1701-1999 & 5.7 & $25.2(1.6)$ & $27.4(1.5)$ & $21.7(1.5)$ & $11.2(1.0)$ \\
\hline 2000-2999 & 17.5 & $22.8(0.8)$ & $27.1(0.9)$ & $21.4(0.7)$ & $11.4(0.5)$ \\
\hline $3000-3999$ & 11.8 & $20.8(0.9)$ & $25.4(1.0)$ & $22.0(1.0)$ & $11.3(0.7)$ \\
\hline $4000-5999$ & 10.5 & $19.8(1.0)$ & $23.7(1.1)$ & $21.2(0.9)$ & $10.8(0.8)$ \\
\hline $6000-8999$ & 4.9 & $20.3(1.4)$ & $23.3(1.5)$ & $19.9(1.4)$ & $11.8(1.1)$ \\
\hline $9000+$ & 4.3 & $18.8(1.5)$ & $24.2(1.7)$ & $24.0(1.6)$ & $13.4(1.2)$ \\
\hline \multicolumn{6}{|c|}{ Educational level (years) } \\
\hline $0-8$ & 8.5 & $25.2(1.5)^{* * *}$ & $31.8(1.3)^{* * *}$ & $11.8(1.1)^{* * *}$ & $2.3(0.5)^{* * *}$ \\
\hline $9-11$ & 12.4 & $28.1(1.2)$ & $31.5(1.1)$ & $22.7(1.1)$ & $9.9(0.7)$ \\
\hline 12 & 31.0 & $23.7(0.7)$ & $30.0(0.6)$ & $22.9(0.7)$ & $10.2(0.4)$ \\
\hline $13-15$ & 25.6 & $24.2(0.8)$ & $28.2(0.7)$ & $27.0(0.9)$ & $14.7(0.6)$ \\
\hline $16+$ & 22.5 & $20.0(0.7)$ & $25.2(0.7)$ & $19.3(0.7)$ & $11.9(0.5)$ \\
\hline \multicolumn{6}{|l|}{ Family size } \\
\hline 1 & 20.4 & $26.6(0.8)^{*}$ & $31.1(0.7)^{* * *}$ & $32.6(1.0)^{* * *}$ & $14.1(0.8)^{* *}$ \\
\hline $2+$ & 79.6 & $22.6(0.5)$ & $27.1(0.5)$ & $19.4(0.4)$ & $10.3(0.3)$ \\
\hline \multicolumn{6}{|l|}{ Area } \\
\hline Urban & 75.6 & $23.3(0.5)$ & $28.5(0.5)^{*}$ & $23.0(0.5)^{* *}$ & $11.9(0.3)^{* * *}$ \\
\hline Rural & 24.4 & $23.8(1.0)$ & $26.5(0.9)$ & $19.5(0.8)$ & $8.7(0.5)$ \\
\hline Unclassified & 0.04 & & & & \\
\hline \multicolumn{6}{|c|}{ Beer tax (cents per drink) } \\
\hline 1 & 15.7 & $22.8(1.1)$ & $25.9(1.2)$ & $22.6(1.0)^{* *}$ & $12.9(0.9)^{* * *}$ \\
\hline $1-1.5$ & 22.7 & $24.1(1.0)$ & $28.3(1.0)$ & $22.4(1.0)$ & $11.3(0.6)$ \\
\hline $1.6-1.91$ & 35.7 & $23.5(0.7)$ & $28.2(0.8)$ & $23.2(0.7)$ & $11.4(0.4)$ \\
\hline $2-3.35$ & 9.3 & $23.4(1.4)$ & $28.7(1.8)$ & $23.9(1.6)$ & $10.8(1.3)$ \\
\hline$>3.35$ & 16.3 & $22.9(1.4)$ & $28.1(1.1)$ & $17.6(1.0)$ & $8.1(0.6)$ \\
\hline Unavailable & 0.35 & & & & \\
\hline \multicolumn{6}{|l|}{ Adjusted Gini } \\
\hline $0.295-0.327$ & 12.2 & $20.26(1.12)^{*}$ & $27.04(1.17)$ & $23.78(1.38)$ & $13.27(1.21)^{*}$ \\
\hline $0.328-0.337$ & 15.9 & $26.32(1.38)$ & $27.16(1.18)$ & $21.86(1.17)$ & $10.74(0.59)$ \\
\hline $0.338-0.347$ & 14.2 & $22.73(1.24)$ & $29.35(1.29)$ & $22.00(1.14)$ & $11.80(0.90)$ \\
\hline $0.348-0.360$ & 19.5 & $25.62(1.02)$ & $29.78(0.99)$ & $23.55(1.06)$ & $11.67(0.79)$ \\
\hline $0.361-0.374$ & 37.9 & $22.52(0.67)$ & $26.96(0.72)$ & $21.07(0.66)$ & $9.92(0.40)$ \\
\hline Unavailable & 0.34 & & & & \\
\hline
\end{tabular}

${ }^{*} p<0.05, * * p<0.001, * * * p \leqslant 0.0001$. 
Table 3

Odds ratios $^{\mathrm{a}}$ for any depressive symptoms vs. none, $95 \%$ confidence intervals

\begin{tabular}{|c|c|c|}
\hline \multirow[t]{2}{*}{ Covariates } & \multicolumn{2}{|c|}{ Odds ratio $(95 \%$ confidence interval) } \\
\hline & Males & Females \\
\hline \multicolumn{3}{|l|}{ Adjusted Gini } \\
\hline $0.295-0.327$ & $0.90(0.77,1.06)$ & $1.09(0.94,1.27)$ \\
\hline $0.328-0.337$ & $1.21(1.03,1.44)$ & $1.04(0.90,1.19)$ \\
\hline $0.338-0.347$ & $1.01(0.87,1.18)$ & $1.17(1.02,1.35)$ \\
\hline $0.348-0.360$ & $1.17(1.02,1.34)$ & $1.18(1.04,1.35)$ \\
\hline $0.361-0.374$ & 1.0 & 1.0 \\
\hline $\begin{array}{l}\text { Median state } \\
\text { income } / 10,000 \$\end{array}$ & $0.91(0.82,1.01)$ & $0.88(0.80,0.98)$ \\
\hline $\begin{array}{l}\text { Doubling family } \\
\text { income }\end{array}$ & $0.91(0.88,0.95)$ & $0.94(0.91,0.96)$ \\
\hline \multicolumn{3}{|l|}{ Age } \\
\hline 18-20 & $1.61(1.33,1.94)$ & $1.68(1.41,2.00)$ \\
\hline $21-30$ & $1.39(1.22,1.58)$ & $1.44(1.29,1.62)$ \\
\hline $31-40$ & $1.25(1.10,1.43)$ & $1.36(1.22,1.51)$ \\
\hline $41-55$ & $1.07(0.94,1.21)$ & $1.25(1.13,1.38)$ \\
\hline $56+$ & 1.0 & 1.0 \\
\hline $\begin{array}{l}\text { Ethnicity (non-white } \\
\text { vs. white) }\end{array}$ & $0.94(0.83,1.06)$ & $1.00(0.90,1.10)$ \\
\hline \multicolumn{3}{|l|}{ Education } \\
\hline $0-8$ & $1.26(1.04,1.51)$ & $1.43(1.23,1.67)$ \\
\hline $9-11$ & $1.36(1.16,1.59)$ & $1.29(1.13,1.47)$ \\
\hline 12 & $1.11(0.98,1.26)$ & $1.07(0.97,1.19)$ \\
\hline $13-15$ & $1.15(1.02,1.31)$ & $1.09(0.98,1.21)$ \\
\hline $16+$ & 1.0 & 1.0 \\
\hline Urban vs. rural & $1.01(0.90,1.15)$ & $1.14(1.04,1.26)$ \\
\hline $\begin{array}{l}\text { Family size (per one } \\
\text { person increase) }\end{array}$ & $0.98(0.95,1.01)$ & $0.96(0.93,0.99)$ \\
\hline
\end{tabular}

$\overline{{ }^{a} \text { Odds ratios reported are adjusted for all the other covariates }}$ shown.

observed across the remaining categories. No clear association between Gini category and depression was observed in women. Prevalence of alcohol dependence symptoms was highest in the lowest Gini category for women. No association between Gini and any alcohol dependence symptom was seen in men. Higher beer tax was associated with reduced prevalence of alcohol dependence symptoms. As would be expected, there was no association between depressive symptoms and beer tax. There was an age gradient for both depressive and alcohol dependence symptoms such that both become less frequent with increasing age. Family income was generally inversely related to depressive symptoms. Alcohol dependence symptoms showed a more complex relationship with family income; a drop from high rates in the lowest income category is followed by a gradual increase for men and women.
Table 4

Odds ratios ( $95 \%$ confidence intervals) for any symptoms of alcohol dependence vs. none

\begin{tabular}{|c|c|c|}
\hline \multirow[t]{2}{*}{ Covariates } & \multicolumn{2}{|c|}{ Odds ratio ( $95 \%$ Confidence interval) } \\
\hline & Males & Females \\
\hline \multicolumn{3}{|l|}{ Adjusted Gini } \\
\hline $0.295-0.327$ & $1.08(0.90,1.30)$ & $1.15(0.91,1.44)$ \\
\hline $0.328-0.337$ & $0.91(0.70,1.18)$ & $0.91(0.68,1.22)$ \\
\hline $0.338-0.347$ & $1.01(0.85,1.21)$ & $1.11(0.89,1.38)$ \\
\hline $0.348-0.360$ & $1.11(0.97,1.27)$ & $1.13(0.97,1.32)$ \\
\hline $0.361-0.374$ & 1.0 & 1.0 \\
\hline \multicolumn{3}{|l|}{ Beer tax } \\
\hline $1-1.5$ & $0.99(0.83,1.18)$ & $0.83(0.69,1.01)$ \\
\hline $1.6-1.9$ & $1.10(0.94,1.29)$ & $0.85(0.71,1.03)$ \\
\hline $2.0-3.35$ & $0.96(0.76,1.21)$ & $0.72(0.54,0.96)$ \\
\hline$>3.35$ & $0.72(0.58,0.89)$ & $0.61(0.47,0.79)$ \\
\hline$<1$ cent per drink & 1.0 & 1.0 \\
\hline $\begin{array}{l}\text { Alcohol control vs. } \\
\text { licensure }\end{array}$ & $1.07(0.88,1.31)$ & $1.08(0.88,1.32)$ \\
\hline $\begin{array}{l}\text { Median state } \\
\text { income } / 10000 \$\end{array}$ & $0.92(0.82,1.03)$ & $0.92(0.81,1.06)$ \\
\hline $\begin{array}{l}\text { Income }<\$ 550 \text { per } \\
\text { month }^{\mathrm{a}}\end{array}$ & $2.10(1.19,3.70)$ & $1.95(1.09,3.47)$ \\
\hline $\begin{array}{l}\text { Doubling family } \\
\text { income }^{\mathrm{b}}\end{array}$ & $1.06(1.01,1.11)$ & $1.06(1.01,1.11)$ \\
\hline \multicolumn{3}{|l|}{ Age } \\
\hline $18-20$ & $7.41(6.09,9.01)$ & $\begin{array}{l}15.68(12.09 \\
20.34)\end{array}$ \\
\hline $21-30$ & $8.36(7.16,9.76)$ & $\begin{array}{l}14.11(11.51 \\
17.30)\end{array}$ \\
\hline $31-40$ & $4.32(3.68,5.06)$ & $8.63(7.00,10.63)$ \\
\hline $41-55$ & $2.66(2.26,3.13)$ & $4.39(3.57,5.40)$ \\
\hline $56+$ & 1.0 & 1.0 \\
\hline $\begin{array}{l}\text { Race (non-white vs. } \\
\text { white) }\end{array}$ & $0.820 .71,0.94)$ & $0.58(0.50,0.67)$ \\
\hline \multicolumn{3}{|l|}{ Education } \\
\hline $0-8$ & $1.06(0.81,1.39)$ & $0.49(0.31,0.78)$ \\
\hline $9-11$ & $1.41(1.18,1.68)$ & $1.29(1.06,1.57)$ \\
\hline 12 & $1.32(1.16,1.50)$ & $1.13(0.98,1.32)$ \\
\hline $13-15$ & $1.31(1.14,1.49)$ & $1.25(1.08,1.44)$ \\
\hline $16+$ years & 1.0 & 1.0 \\
\hline Urban vs. rural & $1.14(1.01,1.29)$ & $1.31(1.12,1.52)$ \\
\hline $\begin{array}{l}\text { Family size (per one } \\
\text { person increase) }\end{array}$ & $0.88(0.84,0.91)$ & $0.78(0.75,0.82)$ \\
\hline
\end{tabular}

Being in the lowest income category (less than $\$ 550$ per month) was associated with higher odds for dependence symptoms $(\mathrm{OR}=2.10,95 \% \mathrm{CI}=(1.19,3.70)$ in men and $\mathrm{OR}=1.95,95 \%$ $\mathrm{CI}=(1.09,3.47)$ in women $)$ compared to all other income groups. At levels above $\$ 550$ per month, income was positively associated with alcohol dependence symptoms $(\mathrm{OR}=$ $1.06(1.01,1.11))$ for doubling income for men and women).

${ }^{a}$ Lowest income category is less than $\$ 550$ per month.

${ }^{\mathrm{b}}$ Range of income category midpoints: $\$ 650-25000$ per month. 
Table 3 shows adjusted OR for relationships between the covariates and reporting any depressive symptoms vs. none in the last 12 months. OR shown are adjusted for all other covariates in the table. The main effects model for the adjusted Gini is shown, as there was no evidence for any interactions between either Gini coefficient and family income, age, and race, and results were the same for raw and adjusted Gini coefficients. The evidence against the null hypothesis of equal odds of any depressive symptoms across adjusted Gini categories, using the adjusted Wald test (Fellegi, 1980), was strong in men $(p=0.008)$ but weak in women $(p=0.062)$. There was no evidence that the odds of depressive symptoms increased with increasing Gini; instead, the OR estimates showed gender-specific nonlinear patterns with ordinal Gini categories. Thus for men, although the lowest odds of any depressive symptoms were observed in the lowest Gini category, the difference between the lowest and highest category was not statistically significant. Significantly increased odds (compared to the highest category) were observed in the second-to-lowest and second-to-highest categories. For women, the lowest odds was observed in the highest Gini category. Significantly increased odds (compared to the highest category) were observed in the middle and second to highest category. For males and females, increasing family income was associated with lower prevalence of any symptoms of depression in the previous year; for a doubling of income the OR is 0.91 (CI 0.88-0.95) for men and 0.94 (CI 0.91-0.96) for women). A negative relationship was found for increased median state income but only for women (OR 0.88 per $\$ 10,000$ increase; (CI $0.80-0.99$ ). Ethnicity was not associated with depressive symptoms after adjustment for other covariates in the model for men or women.

Table 4 shows adjusted OR for relationships between the covariates and reporting any symptoms of alcohol dependence vs. none in the last 12 months. After adjustment for individual-level variables, state median income and alcohol distribution method, a weak negative association between Gini and alcohol dependence was observed in women (not shown). As shown in Table 4, the association observed in women disappeared after additional adjustment for beer tax. No association was observed in men. The highest beer tax category was related to reduced odds of alcohol dependence symptoms for men (OR 0.72; CI 0.58-0.89) while for women this applied to the highest two categories (for 2-3.35 cents OR 0.72; CI 0.54-0.96 and for > 3.35 cents OR 0.61 ; CI $0.47-0.79)$. No relationship was found between dependence symptoms and median state income or alcohol distribution system for men or women. Being in the lowest income category (less than $\$ 550$ per month) was associated with higher odds for dependence symptoms (OR 2.10; CI 1.19-3.70 and OR 1.95; CI
1.09-3.47) compared to all other income groups among both men and women. At levels above $\$ 550$ per month, income was positively associated with the odds of any alcohol dependence symptoms (OR 1.06; CI 1.01-1.11 for doubling of income for men and women). Non-white ethnicity was associated with reduced prevalence of symptoms of dependence in men (OR 0.82; CI 0.710.94 ) and women (OR 0.58; CI 0.50-0.67). There was no evidence of any interactions of Gini by income or Gini by age, or beer tax by age or beer tax by income.

We repeated the analyses for Tables 3 and 4, replacing the categories of any symptoms of depression and alcohol dependence with the DSM-IV diagnoses of Major Depressive Disorder and Alcohol Dependence, respectively. This allows a check for any differences created by our main outcome variables as compared to full diagnoses. For DSM-IV major depression, some pattern emerges in terms of the relationship with income inequality. For women, the odds of major depression decreased with increasing Gini category levels. Compared to the highest Gini category, the lowest Gini category has the highest odds, with adjusted OR 1.38, CI 1.09-1.75. When treating Gini as a continuous variable, a linear trend was significant $(p=0.005)$ on the $\log$ Odds, the adjusted OR 0.94 , CI $0.91-0.98$ for 0.01 increment of Gini. For men, although the overall differences across Gini categories approached statistical significance $(p=0.0554)$, there was no evidence of a linear relationship. Compared with the highest Gini category, the middle Gini category (0.338-0.347) had the lowest odds of major depression, adjusted $\mathrm{OR}=0.67$, $\mathrm{CI}=0.47-0.96$. For DSM-IV alcohol dependence the results are the same as for any symptoms of alcohol dependence both in terms of the inverse relationship with higher beer tax, which again is stronger among women, and the absence of any relationship with income inequality.

\section{Discussion}

We found no evidence for a positive association between state income inequality and symptoms of depression or DSM-IV Major Depressive Disorder over the last year in men or women. This is contrary to results previously reported regarding the relationship between US State income inequality and maternal mental and physical health (Kahn et al., 2000). However, it is consistent with Sturm and Gresenz (2002) and with Weich et al. (2001), who found no relationship between symptoms of common mental disorders and income inequality in US metropolitan and economic areas (Sturm and Gresenz, 2002), and regions consisting of several British counties (Weich et al., 2001). Overall, there was no evidence that increased income inequality is associated with increased alcohol dependence. Increased 
beer taxation was associated with reduced prevalence of dependence symptoms and of DSM-IV alcohol dependence, suggesting that contextual-level variables such as this may be influential. The effects of income inequality and beer taxation did not vary significantly depending on individual-level income; for inequality, this is again contrary to findings that the greater burden of morbidity due to inequality falls disproportionately on those on lower incomes (Kennedy et al., 1998; Kahn et al., 2000; Diez-Roux et al., 2000).

\section{Interpretations}

A recent paper by Lynch, Davey Smith, Kaplan, and House (2000) describes three interpretations of the relationship first described by Wilkinson (1992) between measures of mortality and income inequality in developed countries; the individual income, neomaterial and psychosocial interpretations. According to the individual income interpretation, the association between income inequality and health can be entirely explained by the individual-level association between income and health. Above a certain level of individual income there is little extra benefit to health outcomes. This has been proposed to create a statistical artefact when median income for different populations, rather than individuallevel income, is used to control for the effect of absolute income on the relationship between health and relative income (Gravelle, 1998). However, some (Kennedy et al., 1998; Kahn et al., 2000; Diez-Roux et al., 2000; Lochner et al., 2001) but not all (Fiscella \& Franks, 1997; Daly et al., 1998; Osler et al., 2002; Shibuya et al., 2002; Sturm \& Gresenz, 2002) recent studies controlling for individual-level income show a persisting effect for income inequality, suggesting either contextual determinants of health and/or insufficient adjustment for individual determinants. In our data, income inequality was only weakly associated with the prevalence of any depression symptoms and the prevalence of any alcohol dependence symptoms before adjustment for income (slightly lower prevalence of depression symptoms in the lowest Gini category for men, and higher prevalence of alcohol dependence symptoms in the lowest Gini category for women, as shown in Table 2). After adjustment for state- and individual-level variables there was no evidence that the prevalence of depressive symptoms or alcohol dependence increased with increasing Gini in men or women.

The 'neomaterial' interpretation (Lynch et al., 2000; Davey Smith, 1996) sees greater income inequality as coexisting with a wide range of material conditions relevant to health. These include investment in housing, education and public transport as well as pollution control, healthy food availability and accessibility of healthcare. In our data, income inequality was positively correlated with state policies regarding beer taxation
(Spearman correlation coefficient between beer tax and adjusted Gini: $0.32, p=0.03$ ). In the main effects models, the relationship found for women for inequality effect on alcohol dependence disappeared after controlling for beer tax. Although in this case it was higher income inequality (rather than lower income inequality) that was associated with a 'health protecting' state policy (i.e. alcohol taxation), our findings illustrate the complex relationships involved and the difficulties in isolating an 'inequality effect' from the effects of policies associated with it.

Similarly, it is possible that a 'psychosocial' effect of greater income inequality on rates of symptoms of alcohol dependence could have been obscured by state alcohol policies for which we did not adjust. However, this still leaves the lack of positive association between depression and inequality unexplained in terms of the psychosocial theory.

\section{Limitations and strengths}

The results of the study must be considered in light of the methodology used. For example, the relatively limited variability in inequality across US states may have limited our ability to detect an inequality effect; the range in raw Gini coefficients in our data was $0.38-0.50$ and the range of adjusted Gini is $0.295-0.374$. However, Kahn et al. (2000) found a relationship between state income inequality and poor maternal health using the same census data and the Gini coefficient, suggesting that limited variability was not a problem in this case. The sample design did not facilitate the use of other geographic units in comparative analyses, which would have been useful given the absence of any consensus about the appropriate choice of geographic unit for the study of income inequality and health. For example, two studies have found an independent effect of income inequality on self-rated health (Soobader \& LeClere, 1999) and mortality (Franzini, Ribble, \& Spears, 2001) at the US county level. However, both studies also found that for smaller areas (census tracts and counties with populations under 150,000 , respectively) the effect disappears. It is also possible that, when studying potential psychosocial effects of inequality, larger units such as countries are more relevant than states within a larger country context. Further, corroboration was not available of individual-level income data, although this drawback also characterizes other research in this area. However, the study was characterized by a number of notable strengths. These included the large sample size, the high response rate, and the ability to control for both individual- and state-level confounders such as family income and state alcohol policy. The study also benefited from reliable and valid measures, and limiting the analysis only to those meeting DSM-IV diagnostic criteria for alcohol dependence or depression did not 
give different results; neither did replacing the Gini with the Robin Hood Index (Atkinson \& Mickelwright, 1992), since this is highly correlated with raw Gini in the data used.

From this study, it appears that while family income is strongly associated with prevalence of symptoms of depression and alcohol dependence in both sexes, statelevel income inequality is not a major determinant of the prevalence of alcohol dependence, nor of the prevalence of depression. To our knowledge, this is the third study with these findings. A survey of US adults did not find such a relationship (Sturm \& Gresenz, 2002), but the relatively low response rate $(64 \%)$ may have affected the results. A British study found a more complex relationship (Weich et al., 2001): income inequality was associated with higher prevalence of common mental disorder among respondents with higher incomes, but lower prevalence among those with the lowest incomes. The one positive study is on mothers of young children Kahn et al. (2000). However, there is some evidence that other contextual factors may affect mental health problems, chiefly disorder (defined as a lack of social control reflected by residents' reports of noise, litter, vandalism, graffiti, drug use and trouble with neighbors; Ross, 2000; Cutrona, Russell, Hessling, Brown, \& Murray, 2000; Ross, 2000; Dalgard \& Tambs, 1997; Aneshensel \& Sucoff, 1996) and group density (Halpern, 1993; Halpern \& Nazroo, 1999). This study suggests that as far as alcohol dependence is concerned, state beer tax is an important contextual-level factor. Further research should explore the effect of this and other components of alcohol policy on dependence and other alcohol use disorders.

\section{Acknowledgements}

$\mathrm{CH}$ is funded by a Medical Research Council special training fellowship in health services research. BGL received support from the Robert Wood Johnson Health Policy Investigator Award. DH is supported by NIAAA grant KO2 AA00151 and DH and XL are supported by R01 AA08159.

\section{References}

Alcohol Epidemiology Program. (2000). Alcohol policies in the United States: Highlights from the 50 states. Minneapolis: University of Minnesota.

Aneshensel, C. S., \& Sucoff, C. A. (1996). The neighborhood context of adolescent mental health. Journal of Health and Social Behaviour, 37, 293-310.

Atkinson, A. B., \& Mickelwright, J. (1992). Economic transformation in Eastern Europe and the distribution of income. Cambridge: Cambridge University Press.
Chaloupka, F. J., Grossman, M., \& Saffer, H. (1998). The effects of price on the consequences of alcohol use and abuse. Recent Developments in Alcoholism, 14, 331-346.

Cutrona, C. E., Russell, D. W., Hessling, R. M., Brown, P. A., \& Murray, V. (2000). Direct and moderating effects of community context on the psychological well-being of African American women. Journal of Personality and Social Psychology, 6, 1088-1101.

Dalgard, O. S., \& Tambs, K. (1997). Urban environment and mental health. British Journal of Psychiatry, 171, 530-536.

Daly, M. C., Duncan, G. J., Kaplan, G. A., \& Lynch, J. W. (1998). Macro-to-micro links in the relation between income inequality and mortality. Milbank Quarterly, 76, 315-319.

Davey Smith, G. (1996). Income inequality and mortality: Why are they related? BMJ, 312, 987-988.

Diez-Roux, A. V., Link, B. G., \& Northridge, M. E. (2000). A multilevel analysis of income inequality and cardiovascular disease risk factors. Social Science \& Medicine, 50, 673-687.

Edwards, G., \& Gross, M. M. (1976). Alcohol dependence: Provisional description of a clinical syndrome. $B M J$, 1(6017), 1058-1061.

Fellegi, I. P. (1980). Approximate tests of independence and goodness of fit based on stratified multistage samples. Journal of the American Statistical Association, 75, 261-268.

Fiscella, K., \& Franks, P. (1997). Poverty or income inequality as predictor of mortality: Longitudinal cohort study. $B M J$, 314, 1724-1727.

Franzini, L., Ribble, J., \& Spears, W. (2001). The effects of income inequality and income level on mortality vary by population size in Texas counties. Journal of Health and Social Behavior, 42, 373-387.

Grant, B. F., Harford, T. C., Dawson, D. A., Chou, P., Dufour, M., \& Pickering, R. (1994). Prevalence of DSM-IV alcohol abuse and dependence: United States, 1992. Alcohol Health and Research World, 18, 243-248.

Grant, B. F., Harford, T. C., Dawson, D., Chou, P., \& Pickering, R. (1995). The Alcohol Use Disorder and Associated Disabilities Schedule (AUDADIS): Reliability of alcohol and drug modules in a general population sample. Drug and Alcohol Dependence, 39, 37-44.

Grant, B. F., \& Hasin, D. S. (1992). The alcohol use disorder and associated disabilities interview schedule. Rockville, MD: National Institute on Alcohol Abuse and Alcoholism.

Gravelle, H. (1998). How much of the relation between population mortality and unequal distribution of income is a statistical artefact? $B M J, 316,382-385$.

Halpern, D. (1993). Minorities and mental health. Social Science \& Medicine, 36, 597-697.

Halpern, D., \& Nazroo, J. (1999). The ethnic density effect: Results from a national community survey of England and Wales. International Journal of Social Psychiatry, 46, 34- 46.

Hanna, E. Z., \& Grant, B. F. (1997). Gender differences in DSM-IV alcohol use disorders and major depression as distributed in the general population: Clinical implications. Comprehensive Psychiatry, 38(4), 202-212.

Hasin, D., \& Paykin, A. (1998). Dependence symptoms but no diagnosis: Diagnostic 'orphans' in a community sample. Drug and Alcohol Dependence, 50(1), 19-26.

Hasin, D., \& Paykin, A. (1999). Dependence symptoms but no diagnosis: Diagnostic 'orphans' in a 1992 national sample. Drug and Alcohol Dependence, 53(3), 215-222. 
Hasin, D., Schucit, M., Martin, C. S., Grant, B. F., Bucholz, K. K., \& Helzer, J. E. (2003). Alcohol dependence: What do we know and what do we need to know? Alcoholism Clinical and Experimental Research, in press.

Heath, A. C., Bucholz, K. K., Slutske, W. S., Madden, P. A. F., Dinwiddie, S. H., Dunne, M. P., Statham, D. B., Whitfield, J. B., Martin, N. G., \& Eaves, L. J. (1994). The assessment of alcoholism in surveys of the general community: What are we measuring? Some insights from the Australian twin panel interview survey. International Review on Psychiatry, 6, 295-307.

Horwath, E., Johnson, J., Klerman, G. L., \& Weissman, M. M. (1992). Depressive symptoms as relative and attributable risk factors for first-onset major depression. Archives of General Psychiatry, 49, 817-823.

Johnson, J., Weissman, M. M., \& Klerman, G. L. (1992). Service utilization and social morbidity associated with depressive symptoms in the community. JAMA, 267, $1478-1483$

Judd, L. L., Paulus, M. P., Wells, K. B., \& Rapaport, M. H. (1996). Socioeconomic burden of subsyndromal depressive symptoms and major depression in a sample of the general population. American Journal of Psychiatry, 153, 1411-1417.

Kahn, R. S., Wise, P. H., Kennedy, B. P., \& Kawachi, I. (2000). State income inequality, household income, and maternal mental and physical health: Cross sectional national survey. BMJ, 321, 1311-1315.

Kaplan, G. A., Pamuk, E. R., Lynch, J. W., Cohen, R. D., \& Balfour, J. L. (1996). Inequality in income and mortality in the United States: Analysis of mortality and potential pathways. BMJ, 312, 999-1003.

Kawachi, I., \& Kennedy, B. P. (1997). The relationship of income inequality to mortality: Does the choice of indicator matter. Social Science \& Medicine, 45, $1121-1127$.

Kendler, K. S., \& Gardner, C. O. (1998). Boundaries of major depression: An evaluation of DSM-IV criteria. American Journal of Psychiatry, 155, 172-177.

Kendler, K. S., Kessler, R. C., Walters, E. E., MacLean, C., Neale, M. C., Heath, A. C., \& Eaves, L. J. (1995). Stressful life events, genetic liability, and onset of an episode of major depression in women. American Journal of Psychiatry, 152, 833-842.

Kennedy, B. P., Kawachi, I., Glass, R., \& Prothrow-Stith, D. (1998). Income distribution, socioeconomic status, and self rated health in the United States: Multilevel analysis. BMJ, 317, 917-921.

Kennedy, B. P., Kawachi, I., \& Prothrow-Stith, D. (1996). Income distribution and mortality: Cross sectional ecological study of the Robin Hood index in the United States. BMJ, 312, 1004-1007.

Link, B. G., \& Phelan, J. C. (2000). Evaluating the fundamental cause explanation for social disparities in health. In C. E. Bird, P. Conrad, \& A. M. Fremont (Eds.), Handbook of medical sociology (5th ed) (pp. 33-45). New Jersey: Prentice Hall.

Lochner, K., Pamuk, E., Makuc, D., Kennedy, B. P., \& Kawachi, I. (2001). State-level income inequality and individual mortality risk: A prospective, multilevel study. American Journal of Public Health, 91, 385-391.
Lynch, J., \& Davey Smith, G. (2002). Commentary: Income inequality and health: The end of the story? International Journal of Epidemiology, 31, 549-551.

Lynch, J. W., Davey Smith, G., Kaplan, G. A., \& House, J. S. (2000). Income inequality and mortality: Importance to health of individual income, psychosocial environment, or material conditions. BMJ, 320, 1200-1204.

Lynch, J. W., Kaplan, G. A., Pamuk, E. R., Cohen, R. D., Heck, K. E., \& Balfour, J. L., et al. (1998). Income inequality and mortality in metropolitan areas of the United States. American Journal of Public Health, 88, 1074-1080.

Muthén, B. (1996). Psychometric evaluation of diagnostic criteria: Application to a two-dimensional model of alcohol abuse and dependence. Drug and Alcohol Dependence, 41, $101-112$

Olfson, M., Broadhead, W. E., Weissman, M. M., Leon, A. C., Farber, L., Hoven, C., \& Kathol, R. (1996). Subthreshold psychiatric symptoms in a primary care group practice. Archives of General Psychiatry, 53, 880-886.

Osler, M., Prescott, E., Grønbćk, M., Christensen, U., Due, P., \& Engholm, G. (2002). Income inequality, individual income, and mortality in Danish adults: Analysis of pooled data from two cohort studies. BMJ, 324, 13-16.

Ross, C. (2000). Neighborhood disadvantage and adult depression. Journal of Health and Social Behavior, 41, $177-187$.

Ross, N. A., Wolfson, M. C., Dunn, J. R., Berthelot, J.-M., Kaplan, G. A., \& Lynch, J. W. (2000). Relation between income inequality and mortality in Canada and in the United States: Cross sectional assessment using census data and vital statistics. BMJ, 320, 898-902.

Sarr, M., Bucholz, K. K., \& Phelps, D. L. (2000). Using cluster analysis of alcohol use disorders to investigate 'diagnostic orphans': Subjects with alcohol dependence symptoms but no diagnosis. Drug and Alcohol Dependence, 60(3), 295-302.

Shah, B. V., Barnwell, B. G., \& \&Bieler, G. S. (1997). Software for the statistical analysis of correlated data (SUDAAN) (Release 7.5). Research Triangle Park, NC: Research Triangle Institute.

Shibuya, K., Hashimoto, H., \& Yano, E. (2002). Individual income, income distribution, and self rated health in Japan: Cross sectional analysis of nationally representative sample. BMJ, 324, 16-19.

Soobader, M.-J., \& LeClere, F. B. (1999). Aggregation and the measurement of income inequality: Effects on morbidity. Social Science \& Medicine, 48, 733-744.

Sturm, R., \& Gresenz, C. R. (2002). Relations of income inequality and family income to chronic medical conditions and mental health disorders: National survey. BMJ, 324, 20-25.

Susser, M. (1994). The logic in ecological: 1. The logic of analysis. American Journal of Public Health, 84, 825-829.

Toomey, T. L., \& Wagenaar, A. C. (1999). Policy options for prevention: The case of alcohol. Journal of Public Health Policy, 20, 192-213.

Weich, S., Lewis, G., \& Jenkins, S. P. (2001). Income inequality and the prevalence of common mental disorders in Britain. British Journal of Psychiatry, 178, 222-227.

White, I., Altmann, D. R., \& Nanchahal, K. (2002). Alcohol consumption and mortality: Modelling risks for men and women at different ages. BMJ, 325, 191-194. 
Wilkinson, R. G. (1992). Income distribution and life expectancy. $B M J, 304,165-168$.

Wilkinson, R. G. (1997a). Income, inequality and social cohesion. American Journal of Public Health, 87, 1504 1506 (Comment).
Wilkinson, R. G. (1997b). Health inequalities: Relative or absolute material standards? BMJ, 314, 519-595.

Wilkinson, R. G. (2002). Commentary: Liberty, fraternity, equality. International Journal of Epidemiology, 31, $538-543$. 